\title{
'Too-much-of-a-good-thing'? The role of advanced eco-learning and contingency factors on the relationship between corporate environmental and financial performance
}

\author{
Hengky Latan ${ }^{\mathrm{a}, *}$, Charbel Jose Chiappetta Jabbour ${ }^{\mathrm{b}}$, Ana Beatriz Lopes de Sousa Jabbour ${ }^{\mathrm{b}}$, \\ Douglas William Scott Renwick ${ }^{\mathrm{c}}$, Samuel Fosso Wamba ${ }^{\mathrm{d}}$, Muhammad Shahbaz \\ a Department of Accounting, STIE Bank BPD Jateng, Jl. Pemuda No 4 A Semarang 50139, Indonesia \\ b Montpellier Business School, Montpellier Research in Management, 2300, Avenue des Moulins, 34185 Montpellier, Cédex4, France \\ c College of Business Law and Social Sciences, Nottingham Business School, Nottingham Trent University, Nottingham, UK \\ d Toulouse Business School, Toulouse University, 20 Boulevard Lascrosses, 31068 Toulouse, France
}

\section{A R T I C L E I N F O}

\section{Keywords:}

Environmental accounting

Advanced eco-learning

Contingency factors

Environmental performance

Financial performance

\begin{abstract}
A B S T R A C T
Inspired by the natural-resource-based view (NRBV) theory, we attempt to shed light on a controversy which has been persistent over the last decade, concerning the relationship between corporate environmental performance (CEP) and corporate financial performance (CFP). Using the 'too-much-of-a-good-thing' (TMGT) concept, which suggests that "too much can be worse than too little," we link mixed results and consider the roles of advanced eco-learning and contingency factors in influencing the CEP-CFP relationship. Based on a sample composed of ISO 14001 certified companies in Indonesia, and analyzing the data using consistent Partial Least Squares (PLSc), we found that: the CEP-CFP relationship follows an inverted U-shape; advanced eco-learning is a significant predictor of the CEP-CFP relationship, meaning that organizations able to develop higher eco-learning capability will be better able to identify the ideal boundaries of investment in environmental performance without reducing their financial performance; and that contingency factors such as environmental strategy and firm size have a significant role in influencing the CEP-CFP relationship. The study's limitations, implications for practitioners and a future research agenda are also detailed.
\end{abstract}

\section{Introduction}

The environmental issues faced by society have never been so intensely discussed (Christ and Burritt, 2017; Journeault, 2016; Vastola et al., 2017), as evidenced by the Paris agreement (COP21) - a continuation of the Kyoto protocol-which concluded that every country has the same responsibility to reduce carbon emissions, conserve forests, and increase renewable energy use. As such, companies are beginning to take responsibility for environmental issues and to manage their environmental performance to achieve competitive advantage (Hart and Dowell, 2011; Journeault et al., 2016; Lu and Taylor, 2016; Russo and Fouts, 1997). However, recent debate has not yet reached a resolution as to whether or not improvements in environmental performance (CEP) will be followed by a corresponding rise in financial performance (CFP) (Beurden and Gossling, 2008; Brammer and Millington,
2008; Dixon-Fowler et al., 2013; Grewatsch and Kleindienst, 2015). For example, Molina-Azorín et al. (2009), in their literature review on CEP-CFP, found mixed results and a need to keep exploring this complex relationship.

CEP can be defined as the result of a company's environmental management, which includes use of natural resources, waste disposal, greenhouse gas emissions and water consumption, while CFP can be defined as the economic results derived from the interconnectedness of attributes, actions, and environment. On the one hand, achieving better CEP involves additional costs, such as risk management or extra funding for capital, operations and energy, which in turn leads to a decrease in CFP. On the other hand, improved CEP can lead to better access to markets and product differentiation, which increase CFP (Ambec and Lanoie, 2008; Lankoski, 2008; Stanwick and Stanwick, 1998).

\footnotetext{
* Corresponding author.

Email addresses: latanhengky@gmail.com (H. Latan); c.chiappetta-jabbour@montpellier-bs.com (C.J.C. Jabbour); a.sousa-jabbour@montpellier-bs.com (A.B.L. de Sousa Jabbour); douglas.renwick@ntu.ac.uk (D.W.S. Renwick); s.fosso-wamba@tbs-education.fr (S.F. Wamba); m.shahbaz@montpellier-bs.com (M. Shahbaz)
} 
Although much research has been conducted on the CEP-CFP relationship, the discussion remains mixed and confusing (Grewatsch and Kleindienst, 2015; Trumpp and Guenther, 2017; Ullmann, 1985). Several studies using linear modeling have variously found positive relationships (Journeault, 2016; Russo and Fouts, 1997; Waddock and Graves, 1997), non-significant relationships (Al-Tuwaijri et al., 2004; Henri and Journeault, 2010; Wagner, 2015), and negative relationships (Qi et al., 2014; Tan et al., 2017; Vastola et al., 2017). Other studies using non-linear modeling have found U-shaped relationships (Barnett and Salomon, 2012; Trumpp and Guenther, 2017), inverted U-shaped relationships (Brammer and Millington, 2008; Fujii et al., 2013; Wagner and Blom, 2011) and bidirectional relationships (Martínez-Ferrero and Frías-Aceituno, 2015; Testa and D'Amato, 2017). As Pierce and Aguinis (2013) argue, such inconsistent results arise because of the 'too-much-of-a-good-thing' (TMGT) effect on the CEP-CFP relationship. The TMGT effect is caused by a favorable antecedent/predictor reaching a turning point after which its relationship with the desired result/outcome ceases to be linear, and becomes nonlinear (Pierce and Aguinis, 2013; Vergauwe et al., 2017). Specifically, the relationship between CEP and CFP is expected to change as the value of this particular predictor varies, so that it also serves as a moderator in both relationships.

In this article, we argue that previous research focuses too much on the CEP-CFP relationship, and that there is an opportunity to explore the influence of other concepts on this relationship. In the context of this work, understanding of the CEP-CFP relationship is furthered by adding contingency factors (e.g., firm size, industry type, and environmental strategy) and advanced eco-learning to the classic CEP-CFP dynamic. We argue that the literature on CEP-CFP has provided inconsistent results regarding the validity of the relationship ( $\mathrm{Lu}$ and Taylor, 2016; Trumpp and Guenther, 2017; Ullmann, 1985; Wang and Sarkis, 2017). This diversity of results on the link between CEP and CFP may have arisen due to variables that we further explore in this research. Additionally, the advance represented by the natural-resource-based view (NRBV) theory, as stated by Hart and Dowell (2011), also calls for further investigation of the relationships between advanced eco-learning, CEP and CFP (Guenther et al., 2016). Here, we emphasize that advanced eco-learning acts as an antecedent to the CEP-CFP relationship, provides additional explanatory power and constitutes a key element in influencing it. The purpose of this study is therefore to investigate how the impact of TMGT and the roles of both contingency factors and advanced eco-learning bridge the understanding gap in CEP-CFP relationships in the Indonesian context.

In this work, the concept of advanced eco-learning is anchored in the concept of organizational learning. In order to understand organizational learning, we adopt the perspective of Kloot (1997), for whom 'organizational learning is the process of changing the organization to fit the changed environment'. We argue that organizational learning concerning environmental issues is a topic best suited to firms that adopt advanced and pro-active environmental management measures (Epstein and Roy, 1997). Additionally, advanced eco-learning can enhance firms' performance (Sánchez-Triana and Ortolano, 2001). In this work, advanced eco-learning is derived from the works cited, and deals with the extent to which firms are aware of some of the most compelling contemporary environmental issues, such as climate change, waste management and best practice in business sustainability.

While Indonesia has not been properly studied in terms of the CEP-CFP relationship, and thus presents a valuable opportunity, the relationship may also be affected by national culture (Vastola et al., 2017). It is therefore important to keep investigating different countries in order to build up robust knowledge on CEP-CFP (Albertini, 2013). By exploring the Indonesian context, our findings add a new perspective to the state-of-the-art literature. Moreover, previous studies which have found an inverted U-shape for the CEP-CFP relationship (Fujii et al., 2013; Wagner and Blom, 2011) analyzed either the context of developed countries (e.g. Japan and Sweden) or the context of high profile (e.g. high profitability or technology-based) companies. It is thus relevant to explore the reality of different country and company contexts in order to meaningfully compare such results.

Our work contributes to the literature on this topic by deepening insights into development theory. Primarily, our study extends the understanding of the CEP-CFP relationship by using the meta-theory of TMGT (Pierce and Aguinis, 2013; Vergauwe et al., 2017). Although several previous studies have tested this model using similar concepts (Trumpp and Guenther, 2017), their results have been inconsistent. For example, Wagner and Blom (2011) and Fujii et al. (2013)find an inverted U-shaped CEP-CFP relationship, while Trumpp and Guenther (2017) find a U-shaped relationship using the 'too-little-of-a-good-thing' (TLGT) concept. Our study uses the TMGT concept to further explore the previous findings of Wagner and Blom (2011) and Fujii et al. (2013) by adding evidence from an emerging economy - Indonesia. In doing so, we also explore the perspective proposed by Lankoski (2008), who found the CEP-CFP relationship to be quadratic (inverted U-shaped).

The remainder of this article is organized as follows. The next section presents the relevant theoretical background and development of hypotheses, and is followed by our research method design. Next, we present and discuss our empirical results, and provide implications which may be useful for both academics and practitioners.

\section{Theoretical background and development of hypotheses}

The recent debate on the CEP-CFP relationship has reached one important conclusion; namely, that this relationship is non-linear (Barnett and Salomon, 2012; Fujii et al., 2013; Trumpp and Guenther, 2017; Wagner and Blom, 2011). It is also established that the relationship is important to answering critical questions as to whether "it pays to be green" or "it costs to be green", as put forward in linear-based modeling research (Brammer et al., 2006; Russo and Fouts, 1997; Stanwick and Stanwick, 1998; Waddock and Graves, 1997). The progress of such CEP-CFP research is here supported by the idea of TMGT, which forms the basic philosophical foundation to address the controversy surrounding such research (Pierce and Aguinis, 2013; Vergauwe et al., 2017). The TMGT principle states that "too much of any good thing is ultimately bad", and has become the forerunner in research re-examining the CEP-CFP relationship. However, for a better understanding of the CEP-CFP relationship, the impact of previously omitted variables, such as contingency factors and advanced eco-learning, should also be considered, as we acknowledge and utilize herein (see Beurden and Gossling, 2008; Dixon-Fowler et al., 2013; Grewatsch and Kleindienst, 2015; Lu and Taylor, 2016; Ullmann, 1985). The following sections will explain in more detail the theoretical model and hypotheses proposed in our study, which are illustrated in Fig. 1.

\subsection{It pays to be green or it costs to be green?}

Ever since Porter and Linde (1995) and Hart (1995) proposed hypotheses suggesting the use of environmental management to achieve competitive advantage, support for such propositions has both increased and been challenged. It can be shown by the corroboration of many studies that an increase in CEP will be followed by an increase in CFP, indicating a positive correlation between the two (Beurden and Gossling, 2008; Dixon-Fowler et al., 2013; Henri et al., 2017; Journeault, 2016; Russo and Fouts, 1997). The basic logical argument behind this positive relationship is that pressure for firms to become greener has increased, for example in the case of the ratification of 


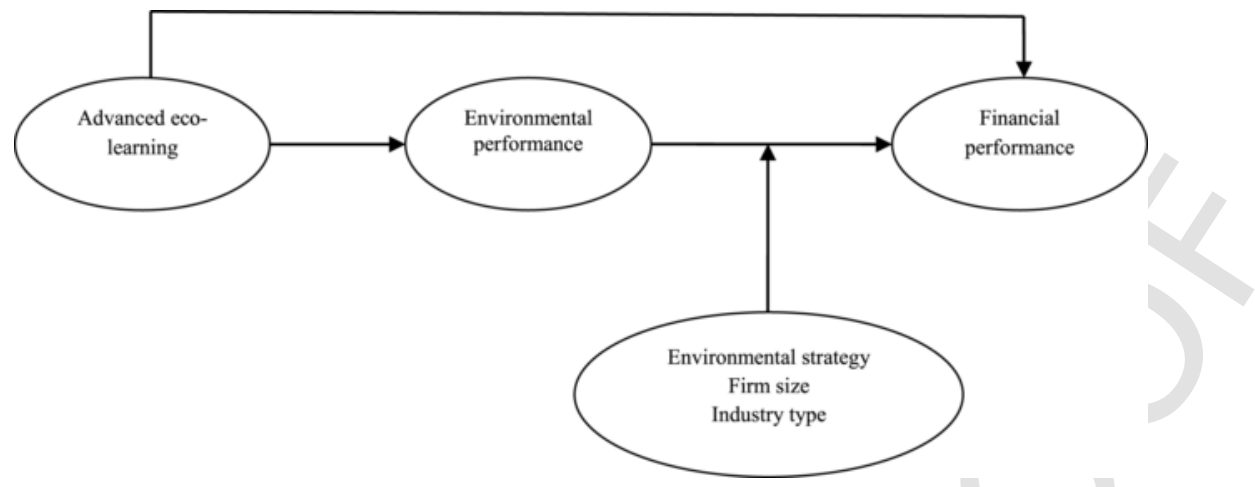

Fig. 1. Conceptual model and relationships among variables.

COP21 for many countries in the world, including Indonesia. This environmental regulation promotes the adoption of environmentally friendly technologies and strategies aimed at achieving efficiency, which ultimately improves CEP and CFP together as a whole (Pondeville et al., 2013; Porter and Linde, 1995). More specifically, companies concerned with CEP will have increased legitimacy and meet stakeholder expectations (Pondeville et al., 2013; Sundin and Brown, 2017), thereby fostering positive corporate image, tax reduction and environmental costs, and ensuring compliance with regulations on a continuous basis (Lankoski, 2008; Rodrigue et al., 2013). Thus, the "it pays to be green" perspective assumes that such measures provide organizational benefits equal to, or greater than, the inherent costs of being greener.

From another perspective, some researchers argue that the CEP-CFP relationship is not always straightforwardly positive, because achieving greener performance may require considerable organizational investment and extra costs (Lankoski, 2008; Trumpp and Guenther, 2017; Vastola et al., 2017).

\subsection{Too-much-of-a-good-thing in the CEP-CFP relationship}

The relationship between CEP and CFP has been debated for the last decade (Dixon-Fowler et al., 2013; Grewatsch and Kleindienst, 2015). The mixed findings on this relationship, including positive, negative and neutral correlations, can be ascribed to the failure of mainstream theories, which are often based on the assumption that "too much can be worse than too little" (Pierce and Aguinis, 2013), also known as the 'too-much-of-a-good-thing' (TMGT) concept. Such thinking is the reason why researchers test linear relationships between predictors and outcomes. However, a linear perspective is one in which the optimal level of the predictor variable in the positive (or negative) relationship tends not to reach the end of the continuum, but appears in the middle of it (Vergauwe et al., 2017). The TMGT effect has inspired authors to re-examine the CEP-CFP relationship (Fujii et al., 2013; Trumpp and Guenther, 2017). The TMGT effect may thus explain why a favorable antecedent (in this case CEP) may cause a decrease or a negative result (in this case on CFP) when its level exceeds a certain threshold, where after the additional cost will exceed the additional benefit generated.

The meta-theory of the TMGT effect assumes that any CEP-CFP relationship as a maximum profit limit, and that an increase beyond this limit will cause a decrease in yield, meaning that the CEP-CFP relationship is predicted to have an inverted U-shape (Lankoski, 2008; Pierce and Aguinis, 2013). Our research adopts this perspective, where an increase in CEP will be followed by CFP up to the maximum extent, and then decline and become negative. As explained by Lankoski (2008), when the marginal cost of improving CFP increases, and marginal revenue decreases, the relationship between CEP and CFP will be inversely proportional, presented as an inverted U-shape. The results of the study by Fujii et al. (2013), which use return on assets (ROA) as an indicator of CFP and an aggregated toxic risk as an indicator of CEP, found a significant inverted U-shaped relationship between CFP and CEP. The same result is echoed by Wagner and Blom (2011), who indicate that the CFP-CEP relationship follows an inverted U-shape. From such thinking, an initial hypothesis pertaining to this relationship is proposed as follows:

H1

The CEP-CFP relationship follows an inverted U-shape.

\subsection{The role of advanced eco-learning in the CEP-CFP relationship}

Several existing studies indicate that environmental capabilities, such as advanced eco-learning, play an important role in supporting the relationship between CEP and CFP (Guenther et al., 2016; Hart, 1995; Hart and Dowell, 2011). Following NRBV theory, environmental capabilities seek to address environmental uncertainties, as well as adhering to existing regulations, in order to improve the links between CEP and CFP. However, in implementing proactive environmental strategies, companies tend to focus on redesigning products and technologies in order to prevent pollution and anticipate future regulation (Rodrigue et al., 2013; Russo and Fouts, 1997; Sen et al., 2015; Wijethilake, 2017). Proactive organizational strategies therefore require organizational learning, which can be understood as an organizational capability in NRBV, thus leading to a positive CEP-CFP relationship (Clarkson et al., 2011; Guenther et al., 2016; Journeault, 2016). As such, advanced eco-learning related to the environment can lead to cost reduction as a result of the more efficient use of natural resources, and improvements in both CEP and CFP.

Furthermore, advanced eco-learning can provide environmental information regarding the effectiveness of a company's past and present environmental activities, and may predict future environmental uncertainties, as well as encouraging environmental awareness and supporting decision-making regarding the future application of processes, products and technologies which will improve CEP and CFP(Guenther et al., 2016; Hart and Dowell, 2011; Journeault, 2016). The concept of advanced eco-learning is derived from the notion of organizational learning, a process whereby organizations change in order to adapt to their environments (Kloot, 1997). Eco-learning is a characteristic of companies that have adopted advanced environmental management practices (Epstein and Roy, 1997; Sánchez-Triana and Ortolano, 2001). In this work, advanced eco-learning deals with companies' awareness of climate change, waste management and best practice regarding business sustainability. There has so far been little exploration of the impact of advanced eco-learning on the CEP-CFP relationship; however, Journeault's research (2016) provides preliminary evidence for environmental capability having an indirect effect on CFP via CEP. From 
such an understanding, our concomitant hypotheses are:

$\mathrm{H} 2 \mathrm{a}$

Advanced eco-learning has a positive and direct effect on CEP.

$\mathrm{H} 2 \mathrm{~b}$

Advanced eco-learning has a positive and indirect effect on CFP through CEP.

\subsection{The role of contingency factors on the CEP-CFP relationship}

Meta-analyses conducted by Dixon-Fowler et al. (2013) and Grewatsch and Kleindienst (2015) demonstrate inconsistency in the role of contingency factors in the CEP-CFP relationship. Beurden and Gossling (2008) state that future research should consider testing the role of contingency factors in the CEP-CFP relationship, as opposed to simply using them as control variables within the model. Gerdin and Greve (2004) further explain that, in order to achieve a suitable model, the placement of contingency factors must be appropriate to the model to provide meaningful results and analysis. Here, we argue that contingency factors such as firm size, industry type and environmental strategy affect the CEP-CFP relationship, thus dividing the study sample into two groups. For example, small companies may have limited financial resources in terms of adopting environmentally friendly ideas; however, they may also have greater flexibility than larger companies (Beurden and Gossling, 2008; Dixon-Fowler et al., 2013; Lucato et al., 2017). Thus, the CEP-CFP relationship depends on the role of such contingency factors. The environmental strategy applied will also affect the CEP-CFP relationship (Journeault, 2016; Solovida and Latan, 2017), where the implementation of proactive versus reactive environmental strategies will affect the company's CEP and CFP (Lisi, 2015; Pondeville et al., 2013). Previous research conducted by Christ and Burritt (2013) and Pondeville et al. (2013) found that contingency factors are important predictor variables in the adoption of environmental management accounting systems, which ultimately affect the CEP-CFP relationship. Henri and Journeault (2010) show that the moderating role of such contingency factors has a significant impact on the relationship between CFP and CEP. Dixon-Fowler et al. (2013), demonstrate that differences between these contingency factors may also affect the CFP-CEP relationship. Therefore, based on the above analysis, our subsequent set of hypotheses are:

\section{H3a}

Environmental strategy moderates the CEP-CFP relationship.

$\mathrm{H} 3 \mathrm{~b}$

Firm size moderates the CEP-CFP relationship.

$\mathrm{H} 3 \mathrm{c}$

Industry type moderates the CEP-CFP relationship.

Fig. 1 illustrates the CEP-CFP relationship, including the testing of contingency factors and advanced eco-learning.

\section{Research methods}

\subsection{Sample selection and data collection}

Our sample consists of two hundred and eighty-five ISO 14001 certified companies, with minimum certification validity of 2016-2019, given that this certification is re-evaluated every three years. The ISO 14001 is an international standard providing guidelines and tools for companies, aiming towards more environmentally friendly process management. For an organization to be awarded ISO 14001 certification, it must have developed an environmental management system according to the ISO 14001 criteria (ISO, 2018). Thus, the sample for our research is based on ISO 14001 companies because these companies are necessarily familiar with environmental management approaches.
The target respondents in this study are general managers, operations managers, financial managers and environmental managers. We argue that these managers have equivalent knowledge and understanding of holistic company goals. To support this assertion, we conducted a $t$-test between CFOs and other managers. The result of this analysis shows no significant difference $(p>0.05)$ between these managers' knowledge ability in this study.

Data was collected using an online survey by placing the questionnaire used to measure each variable on the application platform. Web links to the questionnaire were then emailed to companies, having obtained contact email addresses from the companies' websites. Based on the directory of the Indonesian Ministry of Environment and Forestry and related certification bodies, the 285 companies in our sample included all Indonesian ISO 14001 certified companies. We found that 24 of these companies' certification had expired, and 11 companies were in the process of renewing it. Based on the remaining sample of $250 \mathrm{com}-$ panies, a total of 1000 experts were personally invited to respond to the questionnaire. We sent out an initial invitation to the potential respondents, followed by two additional reminders emails after a two-week period. We assured respondents of the confidentiality and anonymity of their responses and personal information before taking part in our survey. Finally, for the purpose of reducing non-response bias as suggested by Dillman et al. (2014), the time period given to respondents to complete our survey was three months.

At the end of our data collection process, which took place between June and August 2017, we had received 215 questionnaires, of which 23 were incomplete, thus providing 192 fully valid questionnaires. Table 1 shows the profile of our respondents, with the total number of companies involved coming to 67 . We assessed the range of company performance using the Corporate Performance Rating Program (PROPER) as well as respondents' self-declaration ${ }^{1}$ (Cho et al., 2012; Cho and Patten, 2007). The PROPER rating is measured on a scale of five colors ranging from the highest, gold, down to green, blue, red, and black. Gold and green ratings are given to companies that go beyond mere compliance, based on three criteria: (1) implementation of environmental management systems (ISO 14001), (2) use of resources, and (3) implementation of community development initiatives. Criteria measuring companies' compliance with environmental regulations are used for the blue, red, and black rankings. The results oft-testing show that there is no statistically significant difference $(p<0.05)$ between PROPER's rating and manager perception. Such results also confirm that there is no social desirability response bias in respondents' self-reporting in this study (Randall and Fernandes, 2013), and no significant difference between respondents who responded earlier and later, indicating that no systematic bias response occurred (Dillman et al., 2014). We also tested for common method bias (Podsakoff et al., 2012)using a full collinearity approach (Kock, 2017), and found an Average Variance Inflation Factor (AFVIF) value of $<3.3$ which indicates that no common method bias occurs in this study.

\subsection{Measures and scales}

The scales used to measure each variable in our study were adopted from prior studies, and were pre-tested with 19 managers from the target respondents to ensure the intent of each question item was well understood. The results of pre-testing gave us confidence that the questionnaire items were suitable to be used for further analysis, with average loading factor $>0.6$ and Cronbach Alpha >0.7 (Bandalos, 2018; Field, 2016). To measure the environmental strategy variables, we used three question items adopted from Journeault (2016) and Solovida and

\footnotetext{
1 To examine the differences between these two measures, we grouped companie according to PROPER's ratings, and compared this with managers' self-declaration.
} 
Table 1

Profile of Respondents.

\begin{tabular}{lll}
\hline Profile of Respondents & Frequency & Percent \\
\hline Gender & & \\
Male & 136 & 70.83 \\
Female & 56 & 29.17 \\
Total & 192 & $\mathbf{1 0 0 \%}$ \\
Work position & & \\
General managers & 23 & 11.98 \\
Operations managers & 53 & 27.60 \\
Financial managers & 48 & 25.00 \\
Environmental managers & 68 & 35.42 \\
Total & 192 & $100 \%$ \\
Industries & & \\
Food & 28 & 14.58 \\
Textile & 18 & 9.38 \\
Paper & 13 & 6.77 \\
Chemical & 49 & 25.52 \\
Mining & 38 & 19.79 \\
Oil and Gas & 23 & 11.98 \\
Machinery and equipment & 9 & 4.69 \\
Others & 14 & 7.29 \\
Total & 192 & $100 \%$ \\
\hline
\end{tabular}

Latan (2017), where respondents were asked about whether environmental issues are considered in their companies' strategic planning. To distinguish large and small companies, we used code 1 for large companies - those with employee numbers $>100$ - and 0 otherwise (Beurden and Gossling, 2008; Dixon-Fowler et al., 2013). Additionally, we categorised industry types with code 1 for companies working in environmentally sensitive fields - type 1 (such as Chemical, Mining, Oil and Gas) and 0 otherwise - type 2 (Solovida and Latan, 2017). Further, the advanced eco-learning variable was measured using three question items adopted from Journeault (2016), with minor modifications to customize this concept for our research, and saw respondents asked about their awareness of climate change, reducing waste, emissions, recycling and sustainable best practices within their companies. Lastly, the CEP-CFP variables were respectively measured with six and three question items adopted from Henri and Journeault (2010), Lisi (2015) and Solovida and Latan (2017). In regard to CEP respondents were asked about prevention and mitigation of environmental crises, cost-cutting opportunities and limiting environmental impacts, and about operating profit, return on investment (ROI) and operational cash flow for CFP. Table 2 shows the indicators and results of the measurement model for the variables in this study.

As seen in Table 2, the test results for convergent validity and composite reliability reveal a loading factor value of $>0.70$, average variance extracted (AVE) of $>0.50$ and rho $_{-\mathrm{A}}$ of $>0.70$ for each variable, indicating a fit with the rule of thumb assessment of measurement models recommended in the relevant literature (Hair et al., 2017a), meaning that all construct items in this model are reliable and valid. Several variable indicators in the model are retained, with a loading factor value of $<0.5$, which, as per Hair et al. (2017a,b), p. 114, means
Table 2

Construct indicators and measurement model of variables.

\begin{tabular}{|c|c|c|c|c|}
\hline Indicators/Items & Code & FL & AVE & $\mathrm{rho}_{-\mathrm{A}}$ \\
\hline Environmental strategy & & & & \\
\hline $\begin{array}{l}\text { Environmental issues are } \\
\text { explicitly considered within } \\
\text { the company's strategic } \\
\text { planning process }\end{array}$ & ESP1 & 0.827 & & \\
\hline $\begin{array}{l}\text { Consideration for the } \\
\text { environment is addressed } \\
\text { within the company's } \\
\text { mission statement or } \\
\text { statement of business } \\
\text { principles }\end{array}$ & ESP2 & 0.745 & 0.592 & 0.813 \\
\hline $\begin{array}{l}\text { When environmental issues } \\
\text { are considered within the } \\
\text { strategic planning process, } \\
\text { the top management team } \\
\text { makes proactive, forward- } \\
\text { thinking decisions } \\
\text { Advanced eco-learning }\end{array}$ & 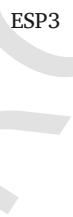 & 0.733 & & \\
\hline $\begin{array}{l}\text { Aware of trends on climate } \\
\text { change }\end{array}$ & AEL1 & 0.791 & & \\
\hline $\begin{array}{l}\text { Aware of trends on } \\
\text { reducing, reusing and } \\
\text { recycling }\end{array}$ & AEL2 & 0.720 & 0.556 & 0.790 \\
\hline $\begin{array}{l}\text { Aware of best practices on } \\
\text { business sustainability }\end{array}$ & AEL3 & 0.726 & & \\
\hline $\begin{array}{l}\text { Environmental performance } \\
\text { Preventing and mitigating } \\
\text { environmental crises }\end{array}$ & CEP1 & 0.651 & & \\
\hline $\begin{array}{l}\text { Uncovering cost cutting } \\
\text { opportunities }\end{array}$ & CEP2 & 0.745 & & \\
\hline $\begin{array}{l}\text { Limiting environmental } \\
\text { impact }\end{array}$ & CEP3 & 0.552 & 0.503 & 0.819 \\
\hline Improved reputation & CEP4 & 0.730 & & \\
\hline Generating societal benefits & CEP5 & 0.786 & & \\
\hline $\begin{array}{l}\text { Increased competitive } \\
\text { advantage } \\
\text { Financial performance }\end{array}$ & CEP6 & 0.764 & & \\
\hline Operating profits & CFP1 & 0.704 & & \\
\hline $\begin{array}{l}\text { Return on investment } \\
\text { (ROI) }\end{array}$ & CFP2 & 0.904 & 0.676 & 0.770 \\
\hline Cash flow from operations & CFP3 & 0.846 & & \\
\hline
\end{tabular}

${ }^{\mathrm{a}} \mathrm{FL}$ i s factor loading.

a low loading value can be retained in order to maintain validity of the content.

In addition to assessing convergent validity, we also tested the discriminant validity or divergent validity of all latent variables used within the model using the Heterotrait-Monotrait (HTMT) ratio, which, as explained by Henseler et al. (2015), is a new procedure in the Partial Least Squares-Path Modeling (PLS-PM) method to test discriminant validity, and is superior to the Fornell-Larcker criterion. Table 3 reveals an HTMT value smaller than 0.90 , which satisfies the recommended rule of thumb (Hair et al., 2017a).

Table 3

Correlations and discriminant validity results.

\begin{tabular}{|c|c|c|c|c|c|c|}
\hline Construct & Mean & S.D & 1 & 2 & 3 & 4 \\
\hline AEL & 3.80 & 0.74 & 1 & 0.870 & 0.828 & 0.701 \\
\hline CEP & 4.03 & 0.65 & $0.610^{*}$ & 1 & 0.694 & 0.739 \\
\hline ESP & 4.02 & 0.75 & $0.524 *$ & $0.529 *$ & 1 & 0.799 \\
\hline CFP & 3.96 & 0.69 & $0.477^{*}$ & $0.587^{*}$ & $0.565^{*}$ & 1 \\
\hline
\end{tabular}

Note: *Correlation is significant at the 0.05 level (2-tailed).

Below the diagonal elements are the correlations between the construct values.

Above the diagonal elements are the HTMT values. 


\subsection{Data analysis}

The PLS-PM method was chosen to analyze the data in this study with the following considerations: 1) PLS-PM is a suitable method for testing quadratic effects, where a feature is available to complete non-linear modeling with various options (Henseler et al., 2012; Ramli et al., 2018); 2) PLS-PM has progressed rapidly, and is able to test theories with the availability of goodness of fit indices (Henseler et al., 2017; Latan and Noonan, 2017); 3) PLS-PM enables researchers to group segmentation (PLS-MGA) easily and to overcome measurement invariance issues in multigroup analysis (Matthews, 2017). Our study uses consistent estimators, or so-called 'consistent PLS' (PLSc) (Dijkstra and Henseler, 2015). Due to the use of PLSc, the required sample size should be large, with not less than 100 cases (Kock and Hadaya, 2018). Previous research in this area has also used PLS-PM as an analysis tool (Lisi, 2015; Pondeville et al., 2013; Solovida and Latan, 2017). Overall, the data analysis for hypothesis testing in our study occurred via five key stages. First, we assessed our measurement model to ensure that all construct indicators were reliable and valid (Bandalos, 2018; Furr, 2017). Second, we assessed our structural model, assessing the suitability of the model with observational data (Aguinis et al., 2018; Hair et al., 2017a). Third, we tested direct and quadratic effects to understand the TMGT effect (Pierce and Aguinis, 2013). Fourth, we tested interaction effects to determine the role of contingency factors in the CEP-CFP relationship (Hayes, 2013). Finally, we performed a multigroup analysis (PLS-MGA) to compare two sub-samples of each path coefficient by assessing measurement invariance (Henseler et al., 2016; Matthews, 2017).

\section{Results}

After confirming that the indicators of all variables were reliable and valid in the first step (see Fig. 2 below), our next step assessed the results of our structural model and hypothesis testing. Since PLS-PM algorithms use the iteration method, following multiple regression series, the path coefficient interpretation in PLS-PM is equal to the standardization of regression coefficients. Similarly, we utilized adjusted r-square, variance inflation factor (VIF), effect size $\left(f^{2}\right)$ and predictive relevance $\left(Q^{2}\right)$ (Hair et al., 2017a; Latan and Noonan, 2017), and PLSc for algorithm selection, and for bootstrapping used the SmartPLS 3 program (Ringle et al., 2015).

Before analyzing results from the second step in more detail, we first tested the collinearity of the structural model. To assess collinearity, we used the same measure in multiple regression, with the recommended VIF values $<3.3$ or $<5$ remaining acceptable for all variable predictors in the model (Hair et al., 2017a). The results of our analysis (see Table 4) show that there is no collinearity problem interfering with our results. Further, we evaluated our structural model by looking at the coefficient of determination $\left(\mathrm{R}^{2}\right.$ or adjusted $\left.\mathrm{R}^{2}\right), f^{2}$ and $Q^{2}$, as the coefficient of determination measures the predictive power of our model, and this coefficient represents the amount of variance in the endogenous variable that can be explained by all exogenous variables. A coefficient of determination above 0.20 can be considered high in some disciplines, but values between 0.25 and 0.50 are generally considered good (Hair et al., 2017a). From the analysis results in Table 4 below, we obtained adjusted $\mathrm{R}^{2}$ values of 0.427 for CEP and 0.464 for CFP, demonstrating that this value indicates a reasonably strong explanatory power. The results of our structural model assessment analysis can be seen in Table 4 below.

In addition to looking at changes in the coefficient of determination, we considered $f^{2}$, which represents the contribution of the individual variance of each variable predictor. As seen in Table 4 , we obtained $f^{2}$ values ranging from $0.014-0.270$, which are classified as small to large. Additionally, we assessed $Q^{2}$ to predict the accuracy of $\mathrm{R}^{2}$, where a $Q^{2}$ value of greater than 0 indicates that the model has predictive power. From our analysis results, $Q^{2}>0$, which means that our model has predictive relevance. For the goodness of fit indices produced by the model through standardized root mean squared residual (SRMR), we obtained a value of $0.094<1.0$, which indicates no discrepancy between an implied model and observed correlation; accordingly, it can be concluded that our model fits with our empirical data. However, Hair et al. (2017a,b), p. 193 suggest that the cut-off value of SRMR is slightly lower for PLS-PM than for CB-SEM because of the different roles of the two algorithms.

\subsection{Hypothesis testing}

In step three, we first tested the direct and quadratic hypotheses, before testing the interaction hypothesis and performing group segmentation comparisons. Here, hypothesis testing was done through a bootstrapping process, with a resample amount of 5,000, and using a 95\% bias-corrected and accelerated (BCa) confidence interval (CI). The non-linear effects we made with quadratic functions are available on SmartPLS with an orthogonalization approach (Hair et al., 2017b; Henseler et al., 2012), an approach which can minimize the problem of collinearity arising from the interaction of two variables. The results of this analysis are presented in Table 5 below:

As shown in Table 5, we identified a TMGT effect with a coefficient value $(\beta)$ of -0.171 , significant at $p=0.002(p=0.039$ at $95 \%$ BCa $\mathrm{CI})$. The negative coefficient value indicates that the CEP-CFP relationship follows an inverted U-shaped pattern. This means that Hypothesis 1 is supported, as is the relevant theory proposed by Lankoski (2008). However, our findings also generalize results obtained by Wagner and Blom (2011) and Fujii et al. (2013), whose studies did not consider TMGT effects. Further, we found the relationship between AEL $\rightarrow$ CEP to be positively significant, with a coefficient value $(\beta)$ of 0.495 , significant at $p=0.000$ (or $p=0.004$ at $95 \%$ BCa CI), meaning that Hypothesis $2 \mathrm{a}$ is also supported. Our results therefore support the findings of Journeault (2016), concluding that environmental capabilities have a significant positive effect on CFP, via CEP. Finally, we found that advanced eco-learning can indirectly affect CFP through CEP with a coefficient $(\beta)$ of 0.165 which is significant at $p=0.000$ (or $p=0.003$ at $95 \%$ $\mathrm{BCa} \mathrm{CI}$ ), meaning that Hypothesis $2 \mathrm{~b}$ is supported. Following the guidelines of Cepeda et al. (2017), we found an indirect effect between AEL $\rightarrow$ $\mathrm{CEP} \rightarrow \mathrm{CFP}$, included in the full mediation category, a result which also supports Journeault's findings above, although we note Journeault's observation (2016) of problems with suppression effects. ${ }^{2}$

\subsection{Additional analyses}

We performed some additional analyses before moving on to the fourth step of our data analysis and hypothesis testing, in order to maintain the robustness of results from prior analysis. As stated by Ullmann (1985) and supported by several researchers (Al-Tuwaijri et al., 2004; Clarkson et al., 2008; Wagner, 2015), the endogeneity problem is one cause of the mixed nature of the CEP-CFP relationship. Endogeneity bias generally arises from non-random sample selection, the existence of reciprocal relationships, or as a result of the influence of omitted variables (Jean et al., 2016; Ketokivi and McIntosh, 2017). Endogeneity bias causes overestimations (Type I error) or underestimations (Type II error) in the PLS algorithm. We undertook additional testing to make sure to negate such issues, and used the Heckman test

\footnotetext{
2 The suppression effect occurs when the direct effect is changed as a result of the influence of a third variable.
} 


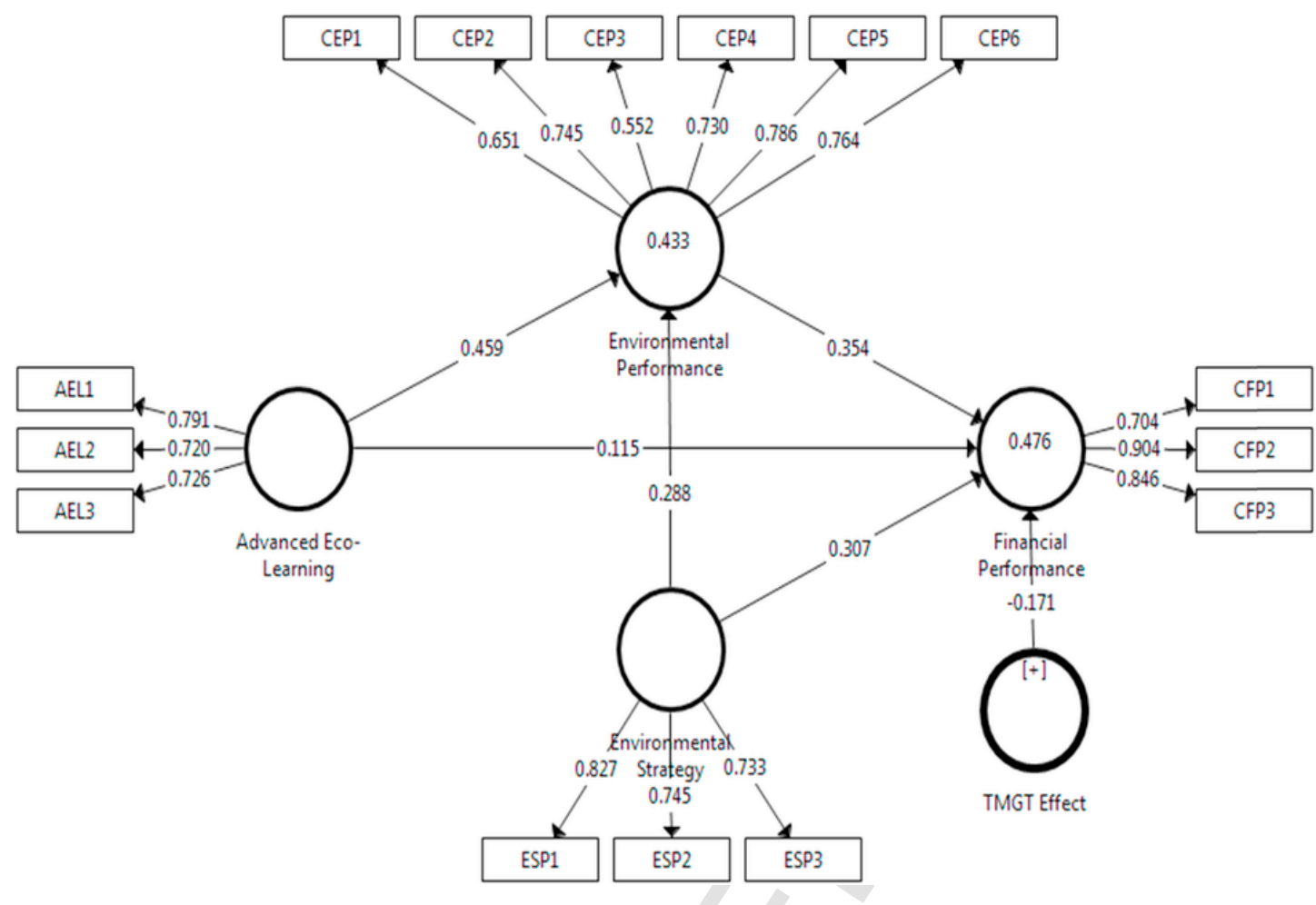

Fig. 2. Evaluation of the measurement model with full sample.

Table 4

Structural model results.

\begin{tabular}{|c|c|c|c|c|c|c|c|}
\hline Constructs & $\mathrm{R}^{2}$ & Adj. $R^{2}$ & $\rightarrow$ & $\mathrm{Q}^{2}$ & VIF & SRMR & AVIF \\
\hline Advanced eco-learning (AEL) & - & - & $0.014-0.270$ & - & 1.776 & - & - \\
\hline Environmental strategy (ESP) & - & - & $0.106-0.117$ & - & 1.539 & - & - \\
\hline Environmental performance (CEP) & 0.433 & 0.427 & 0.136 & 0.423 & 1.764 & 0.094 & 1.589 \\
\hline Financial performance (CFP) & 0.476 & 0.464 & - & 0.462 & - & 0.094 & 1.589 \\
\hline TMGT Effect & - & - & 0.071 & - & 1.018 & - & - \\
\hline
\end{tabular}

Table 5

Relationships between variables-full sample (direct and quadratic effects).

\begin{tabular}{|c|c|c|c|c|c|}
\hline Structural path & Coef $(\beta)$ & S.D & P-Values & $95 \%$ BCa CI & Conclusion \\
\hline $\mathrm{CEP} \times \mathrm{CEP} \rightarrow \mathrm{CFP}$ & -0.171 & 0.059 & $0.002^{* *}$ & $(-0.081,0.039)^{* *}$ & H1 supported \\
\hline $\mathrm{AEL} \rightarrow \mathrm{CEP}$ & 0.495 & 0.062 & $0.000 * *$ & $(0.549,0.004)^{* *}$ & H2a supported \\
\hline $\mathrm{AEL} \rightarrow \mathrm{CEP} \rightarrow \mathrm{CFP}$ & 0.165 & 0.039 & $0.000^{* *}$ & $(0.231,0.003)^{* *}$ & H2b supported \\
\hline
\end{tabular}

Note: **, * statistically significant at the 1 percent and 5 percent levels, respectively.

to obtain propensity scores in assessing endogeneity with the help of the Stata program. We found that the significance obtained from both models remained the same, indicating that endogeneity bias is not a potential threat to our results. From these results, we conclude that our error terms are orthogonal, which means that the model cannot be reversed (Benitez et al., 2018).

\subsection{Interaction effects}

The fourth step of our data analysis examined the interaction effect of contingency factors on the CEP-CFP relationship, in order to understand the significant role played by contingency factors (Hayes, 2013). We used the orthogonalization approach, which produces accurate estimates, has high predictive accuracy and is able to minimize any collinearity problems that arise (Little et al., 2006). The results of our analysis of interaction effects can be seen in Table 6 .
In Table 6 , the interaction between $\mathrm{ESP} \times \mathrm{CEP} \rightarrow \mathrm{CFP}$ is positively significant with a coefficient value $(\beta)$ of 0.182 , and is significant at $p=0.000$ (or $p=0.046$ at $95 \% \mathrm{BCa} C I$ ), meaning that Hypothesis 3a is supported. Our results here confirm previous research conducted by Christ and Burritt (2013), Pondeville et al. (2013) and Solovida and Latan (2017), who all found a significant positive relationship between contingency factors, such as environmental strategies or the adoption of environmental management accounting systems, and CEP-CFP. Further, for the interaction between Size $\times \mathrm{CEP} \rightarrow \mathrm{CFP}$ and Type $\times \mathrm{CEP} \rightarrow \mathrm{CFP}$ our results show no significance for either factor at $p>0.05$ or at $95 \%$ BCa CI, meaning that Hypotheses $3 \mathrm{~b}$ and $3 \mathrm{c}$ are both rejected. These results support previous meta-analysis studies conducted by Beurden and Gossling (2008), Dixon-Fowler et al. (2013) and Grewatsch and Kleindienst (2015). 
Table 6

Relationships between variables-full sample (interaction effects).

\begin{tabular}{|c|c|c|c|c|c|}
\hline Structural path & Coef $(\beta)$ & S.D & P-Values & $95 \%$ BCa CI & Conclusion \\
\hline $\mathrm{ESP} \times \mathrm{CEP} \rightarrow \mathrm{CFP}$ & 0.182 & 0.041 & $0.000 * *$ & $(0.121,0.046)^{*}$ & H3a supported \\
\hline Size $\times$ CEP $\rightarrow$ CFP & 0.075 & 0.052 & $0.072^{\text {n.s }}$ & $(0.099,0.056)^{\mathrm{n} . \mathrm{s}}$ & H3b not supported \\
\hline Type $\times$ CEP $\rightarrow$ CFP & 0.074 & 0.051 & $0.075^{\text {n.s }}$ & $(0.014,0.053)^{\mathrm{n} . \mathrm{s}}$ & H3c not supported \\
\hline
\end{tabular}

Note: **, * statistically significant at the 1 percent and 5 percent levels, respectively.

\subsection{Multigroup analysis (PLS-MGA)}

The last step we undertook was to run a multigroup analysis (PLS-MGA) to compare sub-samples based on firm size (small versus large) and industry type (type 1 versus type 2 ) using permutation tests, and specifically to determine statistically significant differences in the CEP-CFP relationship based on firm size and industry type (Matthews, 2017). Prior to running PLS-MGA, we tested the measurement invariance of composite models (MICOM), with the intention of ensuring that group-specific differences in model estimation do not affect outcomes for latent variables across the group (Henseler et al., 2016). From the analysis of our results (see Table 7) it can be concluded that there is no difference in variance and mean values between the two sub-samples of our group.

To test the whether there is a difference between the two sub-samples in each category, we used 95\% BCa CI, resulting from the permutation test. From the analysis results presented in Table 7, it was found that the relationship between CEP and CFP differed significantly for the firm size category (small versus large), which confirms the Beurden and Gossling's critical review (2008) and addresses previous mixed findings on firm size (Baird et al., 2012; Dixon-Fowler et al., 2013; Grewatsch and Kleindienst, 2015), meaning that Hypothesis $3 \mathrm{~b}$ is supported. However, we did not succeed in proving that the relationship between CEP and CFP differs by industry type, and conclude that industry type differences do not affect the CEP-CFP relationship based on their operations (Lu and Taylor, 2016; Martínez-Ferrero and Frías-Aceituno, 2015).

\section{Discussion}

Overall, our findings suggest that the CEP-CFP relationship follows an inverted U-shape in the Indonesian companies studied here. The most relevant contribution of this work- evidence from Indonesia-fulfils the calls by Vastola et al. (2017) regarding the necessity of considering different cultural contexts when understanding CEP-CFP. The inverted U-shape found is in agreement with the views of Lankoski (2008), although this author focused on the relationship between social responsibility and CFP. Our findings also reinforce the TMGT concept proposed by Pierce and Aguinis (2013), meaning that the trade-off between cost and benefit will be inversely proportional until the frontier point, where after the cost will become greater than the utility. Our findings therefore support previous research conducted by Fujii et al. (2013) and Wagner and Blom (2011), and add further weight to the theoretical perspective of Lankoski (2008). Additionally, our use of linear modeling to examine the CEP-CFP relationship found a positive and significant influence. We also note that linear modeling can be problematic and misleading when it is assumed that utility will continue to grow with additional cost, ignoring Gossen's law. The consequence of our finding here is that there may emerge a cap on investing in environmental improvements in companies, due to the fact that further investment could lead to financial losses.

Moreover, as we found a significant, positive relationship between advanced eco-learning and CEP, our findings support preliminary research conducted by Journeault (2016) and reinforce the propositions of the NRBV theory (Hart and Dowell, 2011). We thus provide early evidence of advancement in NRBV theory (Hart and Dowell, 2011), in which advanced eco-learning is an important predictor of improving CEP, as evidenced by the $f^{2}$ value produced by advanced eco-learning of 0.270 . Here, we also found an indirect influence of advanced eco-learning on CFP through CEP (Journeault, 2016), as a result of improved CEP, where the efficiency of the production process is increased, thus improving CFP. As a consequence of this finding, it can be argued that eco-learning capability could be critical for companies in order to identify the optimum level of investment in environmental improvements to avoid financial losses.

Lastly, we found that some contingency factors have a significant influence on the CEP-CFP relationship; specifically that environmental strategies can moderate the CEP-CFP relationship (Henri and Journeault, 2010). The adoption of proactive environmental strategies will increase CEP and generate added value for products and markets, leading to improved CFP. This reinforces the importance of eco-learning as a critical predictor for understanding the CEP-CFP relationship, because higher eco-learning capability might lead to better environmental strategy. In this way, organizations are able to identify the cap on investment in environmental improvements to avoid financial losses. In addition, as we also found a significant difference in the CEP-CFP relationship based on firm size-a significant positive CEP-CFP relationship in large firms, which could not be confirmed in small firms-our findings support the arguments of Beurden and Gossling (2008) and Grewatsch and Kleindienst (2015) that large companies tend to be greener due to greater stakeholder pressure.

Table 7

PLS-MGA results (sub-sample).

\begin{tabular}{|c|c|c|c|c|c|c|c|}
\hline $\begin{array}{l}\text { Structural } \\
\text { Path }\end{array}$ & Small ( $\beta)$ & Large $(\beta)$ & Differ & $\begin{array}{l}95 \% \text { BCa CI } \\
\text { Permutation }\end{array}$ & MICOM & $\begin{array}{l}\text { Equal } \\
\text { Variances }\end{array}$ & Conclusion \\
\hline \multirow[t]{2}{*}{$\mathrm{CEP} \rightarrow \mathrm{CFP}$} & $0.167^{*}$ & $0.358^{* *}$ & 0.191 & $0.013^{*}$ & $\begin{array}{l}(0.341 ; \\
0.186)^{\mathrm{n} . s}\end{array}$ & Yes & H3b supported \\
\hline & $\begin{array}{l}\text { Type } 1 \\
(\beta)\end{array}$ & $\begin{array}{l}\text { Type } 2 \\
(\beta)\end{array}$ & Differ & $\begin{array}{l}95 \% \text { BCa CI } \\
\text { Permutation }\end{array}$ & MICOM & $\begin{array}{l}\text { Equal } \\
\text { Variances }\end{array}$ & Conclusion \\
\hline $\mathrm{CEP} \rightarrow \mathrm{CFP}$ & $0.360 * *$ & $0.358^{* *}$ & 0.002 & $0.517^{\mathrm{n} . \mathrm{s}}$ & $\begin{array}{l}(0.419 ; \\
0.247)^{\text {n.s }}\end{array}$ & Yes & $\begin{array}{l}\text { H3c not } \\
\text { supported }\end{array}$ \\
\hline
\end{tabular}

n.s., not significant, * $\mathrm{p}<0.05$ (one-tailed test), ${ }^{* *} \mathrm{p}<0.01$ (one-tailed test). 


\section{Conclusions}

As the CEP-CFP relationship is one of the most topical areas of the sustainability debate (Molina-Azorín et al., 2009), and as more evidence from different contexts, such as Indonesia, is required (Albertini, 2013), our study fills an important gap and provides new empirical evidence as follows. First, we found a non-linear CEP-CFP relationship; more precisely, this relationship follows an inverted U-shaped pattern (Fujii et al., 2013; Lankoski, 2008), as proposed by Pierce and Aguinis (2013). Second, we found a strong relationship between advanced eco-learning and CEP-CFP, which answers research calls from Hart and Dowell (2011) and Guenther et al. (2016), and is in line with the NRBV theory. Third, we revealed the role of contingency factors (such as environmental strategy and firm size) on the CEP-CFP relationship, and thus responded to certain critical questions on contingency factors detailed by Beurden and Gossling (2008) and Grewatsch and Kleindienst (2015).

Our research provides both theoretical and practical implications in the following ways. Theoretically, our study provides fresh insight into the advancement of NRBV theory (Hart, 1995; Hart and Dowell, 2011), with previously missing links between advanced eco-learning and CEP-CFP being established. Advanced eco-learning can be a decisive factor in understanding how environmental performance can lead to competitive advantage. When arguing about recent gaps in NRBV (Hart and Dowell, 2011) pointed out that it is necessary to understand how clean technologies will unlock sustainability at the base of the pyramid. We thus suggest that this could be done by investing in advanced eco-learning. As advanced eco-learning is the most important factor in improving CEP, which in turn has implications for CFP, companies with advanced eco-learning will be more aware of the dangers of climate change, and will manage their CEP-CFP to follow best practices of sustainability. Moreover, companies which develop higher eco-learning capability will be able to identify the ideal boundaries of investment in environmental performance, without sacrificing financial performance. Additionally, our study corroborates the theoretical perspective of TMGT and its application in environmental accounting. Indeed, our results deliver new insights for stakeholders about the importance of managing CEP and adopting green ideas, as companies today look not just for profitability, but much more importantly to preserve the natural environment (Deegan, 2017). Moreover, with the ratification of COP21, we believe that companies will also begin to incorporate environmental issues into their key performance indicators (KPIs).

\subsection{Limitations}

Our study has three key limitations that should be considered. First, our study does not take into account organizational culture factors, such as uncertainty avoidance and long-term orientation, which may affect the CEP-CFP relationship. As indicated by Vastola et al. (2017), such factors also play an important role in the CEP-CFP relationship. Second, we only considered the effects of advanced eco-learning as a proxy for environmental capabilities (Hart and Dowell, 2011), without examining other dimensions such as environmental innovation or stakeholder integration (Guenther et al., 2016; Journeault, 2016). Finally, our study only considers contingency factors as a third variable in the CEP-CFP relationship, while a meta-analysis study conducted by Grewatsch and Kleindienst (2015) highlights many other important mediation variables which also demand consideration in future studies.

\subsection{Future research}

Follow-up studies in this area are needed to advance knowledge on the CEP-CFP relationship. First, scholars could consider cultural factors that may affect and provide broader empirical evidence on the CEP-CFP relationship. Second, future research studies may consider testing other third variables that play an important role in the CEP-CFP relationship, which Grewatsch and Kleindienst (2015)group into internal and external factors. Lastly, future research could benefit from conducting replication studies using TMGT scales as proposed by Vergauwe et al. (2017), and extending longitudinal observation periods (Henri et al., 2017), to reinforce our findings on the CEP-CFP relationship.

\section{References}

Aguinis, H., Ramani, R.S., Alabduliader, N., 2018. What you see is what you get? Enhancing methodological transparency in management research. Acad. Manag. Ann. $12,1-28$.

Al-Tuwaijri, S.A., Christensen, T.E., Hughes, K.E., 2004. The relations among environmental disclosure, environmental performance, and economic performance: a simultaneous equations approach. Account. Organ. Soc. 29, 447-471.

Albertini, E., 2013. Does environmental management improve financial performance? A meta-analytical review. Organ. Environ. 26, 431-457.

Ambec, S., Lanoie, P., 2008. Does it pay to be green? A systematic overview. Acad. Manag. Perspect. 22, 45-62.

Baird, P.L., Geylani, P.C., Roberts, J.A., 2012. Corporate social and financial performance re-examined: industry effects in a linear mixed model analysis. J. Bus. Ethics 109, 367-388.

Bandalos, D.L., 2018. Measurement Theory and Applications for the Social Sciences. Guilford Press, New York.

Barnett, M.L., Salomon, R.M., 2012. Does it pay to be really good? Addressing the shape of the relationship between social and financial performance. Strat. Manag. J. 33, 1304-1320.

Benitez, J., Ray, G., Henseler, J., 2018. Impact of information technology infrastructure flexibility on mergers and acquisitions. MIS Q. 41, 25-43.

Beurden, P.v., Gossling, T., 2008. The worth of values - a literature review on the relation between corporate social and financial performance. J. Bus. Ethics 82, 407-424.

Brammer, S., Brooks, C., Pavelin, S., 2006. Corporate social performance and stock returns: UK evidence from disaggregate measures. Financ. Manag. 35, 97-116.

Brammer, S., Millington, A., 2008. Does it pay to be different? An analysis of the relationship between corporate social and financial performance. Strat. Manag. J. 29, 1325-1343.

Cepeda, G., Nitzl, C., Roldán, J.L., 2017. Mediation analyses in partial least squares structural equation modeling: guidelines and empirical examples. In: Latan, H., Noonan, R. (Eds.), Partial Least Squares Path Modeling: Basic Concepts, Mhodological Issues and Applications. Springer International Publishing, Cham, pp. 173-195.

Cho, C.H., Guidry, R.P., Hageman, A.M., Patten, D.M., 2012. Do actions speak louder than words? An empirical investigation of corporate environmental reputation. Account Organ. Soc. 37, 14-25.

Cho, C.H., Patten, D.M., 2007. The role of environmental disclosures as tools of legitimacy: a research note. Account. Organ. Soc. 32, 639-647.

Christ, K.L., Burritt, R.L., 2013. Environmental management accounting: the significance of contingent variables for adoption. J. Clean. Prod. 41, 163-173.

Christ, K.L., Burritt, R.L., 2017. Supply chain-oriented corporate water accounting: a research agenda. Sustain. Account. Manag. Policy J. 8, 216-242.

Clarkson, P.M., Li, Y., Richardson, G.D., Vasvari, F.P., 2008. Revisiting the relation between environmental performance and environmental disclosure: an empirical analysis. Account. Organ. Soc. 33, 303-327.

Clarkson, P.M., Li, Y., Richardson, G.D., Vasvari, F.P., 2011. Does it really pay to be green? Determinants and consequences of proactive environmental strategies. J. Account. Public Policy 30, 122-144.

Deegan, C., 2017. Twenty five years of social and environmental accounting research within Critical Perspectives of Accounting: hits, misses and ways forward. Crit. Perspect. Account. 43, 65-87.

Dijkstra, T.K., Henseler, J., 2015. Consistent and asymptotically normal PLS estimators for linear structural equations. Comput. Stat. Data Anal. 81, 10-23.

Dillman, D.A., Smyth, J.D., Christian, L.M., 2014. Internet, Phone, Mail, and Mixed Mode Surveys: the Tailored Design Method, fourth ed. Wiley, Hoboken, NJ.

Dixon-Fowler, H.R., Slater, D.J., Johnson, J.L., Ellstrand, A.E., Romi, A.M., 2013. Beyond "does it pay to be green?" A meta-analysis of moderators of the CEP-CFP relationship. J. Bus. Ethics 112, 353-366.

Epstein, M.J., Roy, M.J., 1997. Using ISO 14000 for improved organizational learning and environmental management. Environ. Qual. Manag. 7, 21-30.

Field, A., 2016. An Adventure in Statistics: the Reality Enigma. Sage Publications, Thousand Oaks.

Fujii, H., Iwata, K., Kaneko, S., Managi, S., 2013. Corporate environmental and economic performance of Japanese manufacturing firms: empirical study for sustainable development. Bus. Strategy Environ. 22, 187-201.

Furr, R.M., 2017. Psychometrics: an Introduction. Sage Publications, Thousand Oaks.

Gerdin, J., Greve, J., 2004. Forms of contingency fit in management accounting research: a critical review. Account. Organ. Soc. 29, 303-326. 
Grewatsch, S., Kleindienst, I., 2015. When does it pay to be good? Moderators and mediators in the corporate sustainability-corporate financial performance relationship: a critical review. J. Bus. Ethics 1-34.

Guenther, E., Endrikat, J., Guenther, T.W., 2016. Environmental management control systems: a conceptualization and a review of the empirical evidence. J. Clean. Prod. 136, 147-171.

Hair, J.F., Hult, G.T.M., Ringle, C.M., Sarstedt, M., 2017a. A Primer on Partial Least Squares Structural Equation Modeling (PLS-sem), second ed. Sage Publications, Thousand Oaks.

Hair, J.F., Sarstedt, M., Ringle, C.M., Gudergan, S.P., 2017b. Advances Issues in Partial Least Squares Structural Equation Modeling. Sage Publications, Thousand Oaks.

Hart, S.L., 1995. A natural-resource-based view of the firm. Acad. Manag. Rev. 20, 986-1014.

Hart, S.L., Dowell, G., 2011. A natural-resource-based view of the firm: fifteen years after. J. Manag. 37, 1464-1479.

Hayes, A.F., 2013. Introduction to Mediation, Moderation, and Conditional Process Analysis: a Regression-based Approach. Guilford Press, New York.

Henri, J.-F., Journeault, M., 2010. Eco-control: the influence of management control systems on environmental and economic performance. Account. Organ. Soc. 35, 63-80.

Henri, J.-F., Journeault, M., Brousseau, C., 2017. Eco-control change and environmental performance: a longitudinal perspective. J. Account. Organ. Change 13, 188-215.

Henseler, J., Fassott, G., Dijkstra, T.K., Wilson, B., 2012. Analysing quadratic effects of formative constructs by means of variance-based structural equation modelling. Eur. J. Inf. Syst. 21, 99-112.

Henseler, J., Hubona, G., Ray, P.A., 2017. Partial least squares path modeling: updated guidelines. In: Latan, H., Noonan, R. (Eds.), Partial Least Squares Path Modeling: Basic Concepts, Methodological Issues and Applications. Springer International Publishing, Cham, pp. 19-39.

Henseler, J., Ringle, C.M., Sarstedt, M., 2015. A new criterion for assessing discriminant validity in variance-based structural equation modeling. J. Acad. Mark. Sci. 43, $115-135$.

Henseler, J., Ringle, C.M., Sarstedt, M., 2016. Testing Measurement invariance of composites using partial least squares. Int. Mark. Rev. 33, 405-431.

Jean, R.-J.B., Deng, Z., Kim, D., Yuan, X., 2016. Assessing endogeneity issues in international marketing research. Int. Mark. Rev. 33, 483-512.

Journeault, M., 2016. The influence of the eco-control package on environmental and economic performance: a natural resource-based approach. J. Manag. Account. Res. 28, $149-178$.

Journeault, M., Ronge, Y.D., Henri, J.-F., 2016. Levers of eco-control and competitive environmental strategy. Br. Account. Rev. 48, 316-340.

Ketokivi, M., McIntosh, C.N., 2017. Addressing the endogeneity dilemma in operations management research: theoretical, empirical, and pragmatic considerations. J. Oper. Manag. 52, 1-14.

Kloot, L., 1997. Organizational learning and management control systems: responding to environmental change. Manag. Account. Res. 8, 47-73.

Kock, N., 2017. Common methods bias: a full collinearity assessment method for PLS-SEM. In: Latan, H., Noonan, R. (Eds.), Partial Least Squares Path Modeling: Basic Concepts, Methodological Issues and Applications. Springer International Publishing, Cham.

Kock, N., Hadaya, P., 2018. Minimum sample size estimation in PLS-SEM: the inverse square root and gamma-exponential methods. Inf. Syst. J. 28, 227-261.

Lankoski, L., 2008. Corporate responsibility activities and economic performance: a theory of why and how they are connected. Bus. Strategy Environ. 17, 536-547.

Latan, H., Noonan, R., 2017. Partial Least Squares Path Modeling: Basic Concepts, Methodological Issues and Applications. Springer International Publishing, Cham.

Lisi, I.E., 2015. Translating environmental motivations into performance: the role of environmental performance measurement systems. Manag. Account. Res. 29, 27-44.

Little, T.D., Bovaird, J.A., Widaman, K.F., 2006. On the merits of orthogonalizing powered and product terms: implications for modeling interactions among latent variables. Struct. Equ. Model. 13, 497-519.

Lu, W.L., Taylor, M.E., 2016. Which factors moderate the relationship between sustainability performance and financial performance? A meta-analysis study. J. Int. Account. Res. 15, 1-15.

Lucato, W.C., Costa, E.M., Neto, G.C.D.O., 2017. The environmental performance of SMEs in the Brazilian textile industry and the relationship with their financial performance. J. Environ. Manag. 203, 550-556.

Martínez-Ferrero, J., Frías-Aceituno, J.V., 2015. Relationship between sustainable development and financial performance: international empirical research. Bus. Strategy Environ. 24, 20-39.

Matthews, L.M., 2017. Applying multigroup analysis in PLS-SEM: a step-by-step process. In: Latan, H., Noonan, R. (Eds.), Partial Least Squares Path Modeling: Basic Concepts, Methodological Issues and Applications. Springer International Publishing, Cham, pp. 219-243.
Molina-Azorín, J.F., Claver-Cortés, E., López-Gamero, M.D., Tarí, J.J., 2009. Green management and financial performance: a literature review. Manag. Decis. 47, $1080-1100$.

Pierce, J.R., Aguinis, H., 2013. The too-much-of-a-good-thing effect in management. J. Manag. 39, 313-338.

Podsakoff, P.M., MacKenzie, S.B., Podsakoff, N.P., 2012. Sources of method bias in socia science research and recommendations on how to control it. Annu. Rev. Psychol. 63, 539-569.

Pondeville, S., Swaen, V., Rongé, Y.D., 2013. Environmental management control systems: the role of contextual and strategic factors. Manag. Account. Res. 24, 317-332.

Porter, M.E., Linde, C.V.D., 1995. Toward a new conception of the environment-competitiveness relationship. J. Econ. Perspect. 9, 97-118.

Qi, G.Y., Zeng, S.X., Shi, J.J., Meng, X.H., Lin, H., Yang, Q.X., 2014. Revisiting the relationship between environmental and financial performance in Chinese industry. J. Environ. Manag. 145, 349-356.

Ramli, N.A., Latan, H., Nartea, G.V., 2018. Why should PLS-SEM be used rather than regression? Evidence from the capital structure perspective. In: Avkiran, N.K., Ringle, C.M. (Eds.), Partial Least Squares Structural Equation Modeling: Recent Advances in Banking and Finance. Springer International, Cham, pp. 171-209.

Randall, D.M., Fernandes, M.F., 2013. The social desirability response bias in ethics research. In: Michalos, A.C., Poff, D.C. (Eds.), Citation Classics from the Journal of Business Ethics: Celebrating the First Thirty Years of Publication. Springer, New York, pp. 173-190.

Ringle, C.M., Wende, S., Becker, J.-M., 2015. SmartPLS 3. SmartPLS GmbH, Boenningstedt

Rodrigue, M., Magnan, M., Boulianne, E., 2013. Stakeholders' influence on environmental strategy and performance indicators: a managerial perspective. Manag. Account. Res. 24, 301-316.

Russo, M.V., Fouts, P.A., 1997. A resource-based perspective on corporate environmental performance and profitability. Acad. Manag. J. 40, 534-559.

Sánchez-Triana, E., Ortolano, L., 2001. Organizational learning and environmental impact assessment at Colombia's Cauca Valley Corporation. Environ. Impact Assess. Rev. 21 223-239.

Sen, P., Roy, M., Pal, P., 2015. Exploring role of environmental proactivity in financial performance of manufacturing enterprises: a structural modelling approach. J. Clean. Prod. 108, 583-594.

Solovida, G.T., Latan, H., 2017. Linking environmental strategy to environmental performance: mediation role of environmental management accounting. Sustain. Account. Manag. Policy J. Forthcom.

Stanwick, P.A., Stanwick, S.D., 1998. The relationship between corporate social performance, and organizational size, financial performance, and environmental performance: an empirical examination. J. Bus. Ethics 17, 195-204.

Sundin, H., Brown, D.A., 2017. Greening the black box: integrating the environment and management control systems. Account. Audit. Account. J. 30, 620-642.

Tan, S.-H., Habibullah, M.S., Tan, S.-K., Choon, S.-W., 2017. The impact of the dimensions of environmental performance on firm performance in travel and tourism industry. J. Environ. Manag. 203, 603-611.

Testa, M., D'Amato, A., 2017. Corporate environmental responsibility and financial performance: does bidirectional causality work? Empirical evidence from the manufacturing industry. Soc. Responsib. J. 13, 221-234.

Trumpp, C., Guenther, T., 2017. Too little or too much? Exploring U-shaped relationships between corporate environmental performance and corporate financial performance. Bus. Strategy Environ. 26, 49-68.

Ullmann, A.A., 1985. Data in search of a theory: a critical examination of the relationships among social performance, social disclosure, and economic performance of U.S. firms. Acad. Manag. Rev. 10, 540-557.

Vastola, V., Russo, A., Vurro, C., 2017. Dealing with cultural differences in environmental management: exploring the CEP-CFP relationship. Ecol. Econ. 134, 267-275.

Vergauwe, J., Wille, B., Hofmans, J., Kaiser, R.B., Fruyt, F.D., 2017. The too little/too much scale: a new rating format for detecting curvilinear effects. Organ. Res. Methods 20, 518-544.

Waddock, S.A., Graves, S.B., 1997. The corporate social performance-financial link. Strat Manag. J. 18, 303-319.

Wagner, M., 2015. The link of environmental and economic performance: drivers and limitations of sustainability integration. J. Bus. Res. 68, 1306-1317.

Wagner, M., Blom, J., 2011. The reciprocal and non-linear relationship of sustainability and financial performance. Bus. Ethics A Eur. Rev. 20, 418-432.

Wang, Z., Sarkis, J., 2017. Corporate social responsibility governance, outcomes, and financial performance. J. Clean. Prod. 162, 1607-1616.

Wijethilake, C., 2017. Proactive sustainability strategy and corporate sustainability performance: the mediating effect of sustainability control systems. J. Environ. Manag. 196, 569-582. 